Virginia Commonwealth University VCU Scholars Compass

1995

\title{
Effect of Oral Alendronate on Bone Mineral Density and the Incidence of Fractures in Postmenopausal Osteoporosis
}

Uri A. Liberman, M.D., Ph.D.

Tel Aviv University, Beilinson Medical Center

Stuart R. Weiss , M.D.

San Diego Endocrine and Medical Clinic

Johann Bröll , M.D.

Kaiser Franz Josef Hospital

See next page for additional authors

Follow this and additional works at: http://scholarscompass.vcu.edu/intmed_pubs

Part of the Medicine and Health Sciences Commons

From The New England Journal of Medicine, Liberman, U.A., Weiss, S.R., Bröll, J., et al., Effect of Oral Alendronate on Bone Mineral Density and the Incidence of Fractures in Postmenopausal Osteoporosis, Vol. 333, Page 1437, Copyright (C) 1995 Massachusetts Medical Society. Reprinted with permission.

\section{Downloaded from}

http://scholarscompass.vcu.edu/intmed_pubs/51

This Article is brought to you for free and open access by the Dept. of Internal Medicine at VCU Scholars Compass. It has been accepted for inclusion in Internal Medicine Publications by an authorized administrator of VCU Scholars Compass. For more information, please contact libcompass@vcu.edu. 


\section{Authors}

Uri A. Liberman , M.D., Ph.D.; Stuart R. Weiss , M.D.; Johann Bröll , M.D.; Helmut W. Minne , M.D.; Hui Quan , Ph.D.; Norman H. Bell , M.D.; Jose Rodriguez-Portales , M.D.; Robert W. Downs , Jr., M.D.; Jan

Dequeker , M.D., Ph.D.; Murray Favus , M.D.; Ego Seeman , M.D.; Robert R. Recker , M.D.; Thomas Capizzi , Ph.D.; Arthur C. Santora , M.D., Ph.D.; Antonio Lombardi , M.D.; Raksha V. Shah , M.A., R.D.; Laurence J. Hirsch , M.D.; and David B. Karpf, M.D. 


\section{The New England Journal of Medicine}

CCopyright, 1995, by the Massachusetts Medical Society

\section{EFFECT OF ORAL ALENDRONATE ON BONE MINERAL DENSITY AND THE INCIDENCE OF FRACTURES IN POSTMENOPAUSAL OSTEOPOROSIS}

Uri A. Liberman, M.D., Ph.D., Stuart R. Weiss, M.D., Johann Bröll, M.D., Helmut W. Minne, M.D., Hui Quan, Ph.D., Norman H. Bell, M.D., Jose Rodriguez-Portales, M.D., Robert W. Downs, Jr., M.D., Jan Dequeker, M.D., Ph.D., Murray Favus, M.D., Ego Seeman, M.D., Robert R. Regker, M.D., Thomas Capizzi, Ph.D., Arthur G. Santora II, M.D., Ph.D., Antonio Lombardi, M.D., Raksha V. Shah, M.A., R.D., Laurence J. Hirsch, M.D., and David B. Karpf, M.D., for the Alendronate Phase III Osteoporosis Treatment Study Group*

\begin{abstract}
Background. Postmenopausal osteoporosis is a serious health problem, and additional treatments are needed.

Methods. We studied the effects of oral alendronate, an aminobisphosphonate, on bone mineral density and the incidence of fractures and height loss in 994 women with postmenopausal osteoporosis. The women were treated with placebo or alendronate $(5$ or $10 \mathrm{mg}$ daily for three years, or $20 \mathrm{mg}$ for two years followed by $5 \mathrm{mg}$ for one year); all the women received $500 \mathrm{mg}$ of calcium daily. Bone mineral density was measured by dual-energy $\mathrm{x}$-ray absorptiometry. The occurrence of new vertebral fractures and the progression of vertebral deformities were determined by an analysis of digitized radiographs, and loss of height was determined by sequential height measurements.
\end{abstract}

Results. The women receiving alendronate had significant, progressive increases in bone mineral density at all skeletal sites, whereas those receiving placebo had decreases in bone mineral density. At three years, the mean $( \pm S E)$ differences in bone mineral density be-

$\mathrm{P}$ OSTMENOPAUSAL osteoporosis is a common disorder characterized by an increase in bone resorption relative to bone formation, generally in conjunction with an increased rate of bone turnover. ${ }^{1}$ The progressive decrease in bone mass leads to an increased sus-

From the Department of Metabolic Disease, Beilinson Medical Center, Tel Aviv University, Petah-Tikva, Israel (U.A.L.); the San Diego Endocrine and Medical Clinic, San Diego, Calif. (S.R.W.); the Department of Medicine, Kaiser Franz Josef Hospital, Vienna, Austria (J.B.); Klinik der Fürstenhof, Bad Pyrmont, Germany (H.W.M.); Merck Research Laboratories, Rahway, N.J. (H.Q., T.C., A.C.S., A.L., R.V.S., L.J.H., D.B.K.); the Department of Research Services, Veterans Affairs Medical Center, Charleston, S.C. (N.H.B.); the Department of Endocrinology, School of Medicine, Catholic University of Chile, Santiago (J.R.-P.); the Department of Medicine, Medical College of Virginia, Richmond (R.W.D.); the Department of Rheumatology, Catholic University Leuven, Leuven, Belgium (J.D.); the Department of Medicine, University of Chicago, Chicago (M.F.); the Department of Endocrinology, Austin Hospital, Heidelberg, Australia (E.S.); and the Center for Osteoporosis Research, Creighton University, Omaha, Nebr. (R.R.R.). Address reprint requests to Dr. Liberman at Metabolic Diseases, Beilinson Medical Center, 49100, Petah-Tikva, Israel.

Supported by a grant from Merck Research Laboratories.

Presented in part at the 77th Annual Meeting of the Endocrine Society, Washington, D.C., June 14-17, 1995.

*The other members of the Alendronate Phase III Osteoporosis Treatment Study Group are listed in the Appendix. tween the women receiving $10 \mathrm{mg}$ of alendronate daily and those receiving placebo were $8.8 \pm 0.4$ percent in the spine, $5.9 \pm 0.5$ percent in the femoral neck, $7.8 \pm 0.6$ percent in the trochanter, and $2.5 \pm 0.3$ percent in the total body ( $\mathrm{P}<0.001$ for all comparisons). The 5 -mg dose was less effective than the 10-mg dose, and the regimen of $20 \mathrm{mg}$ followed by $5 \mathrm{mg}$ was similar in efficacy to the $10-\mathrm{mg}$ dose. Overall, treatment with alendronate was associated with a 48 percent reduction in the proportion of women with new vertebral fractures (3.2 percent, vs. 6.2 percent in the placebo group; $P=0.03)$, a decreased progression of vertebral deformities (33 percent, vs. 41 percent in the placebo group; $P=0.028)$, and a reduced loss of height $(P=0.005)$ and was well tolerated.

Conclusions. Daily treatment with alendronate progressively increases the bone mass in the spine, hip, and total body and reduces the incidence of vertebral fractures, the progression of vertebral deformities, and height loss in postmenopausal women with osteoporosis. (N Engl J Med 1995;333:1437-43.)

ceptibility to fractures, which result in substantial morbidity and mortality. ${ }^{2}$ Vertebral fractures are important not only because they can cause pain, kyphosis, and height loss but also because they predict subsequent, nonvertebral fractures independently of bone mineral density. ${ }^{3}$ Although there are several risk factors for fractures, reduced bone mineral density is the strongest predictor. ${ }^{4}$ Thus, the ultimate goal of pharmacologic treatment in women with postmenopausal osteoporosis is to reduce the risk of fractures by increasing bone mass of normal quality.

The clinically useful bisphosphonates are synthetic analogues of inorganic pyrophosphate, an endogenous regulator of bone turnover that inhibits bone resorption and mineralization in vitro. ${ }^{5}$ All bisphosphonates have a high affinity for hydroxyapatite but, unlike pyrophosphate, are resistant to metabolism by endogenous phosphatases. ${ }^{5,6}$ Bisphosphonates are capable of inhibiting bone mineralization at roughly equivalent doses; however, their potencies for the inhibition of bone resorption depend on the unique chemical structure of their 
side chains. ${ }^{7}$ The four-carbon amino side chain of alendronate conveys a very high potency, which in turn permits effective inhibition of osteoclast-mediated bone resorption at doses that do not impair bone mineralization, ${ }^{6}$ even with daily doses, which is not the case with etidronate..$^{8,9}$ Treatment with alendronate specifically inhibits increased bone resorption and thereby normalizes the rate of bone turnover. ${ }^{10}$ Preclinical evaluations of alendronate in animals with osteoporosis have documented greater bone strength in accordance with increased bone mass, ${ }^{11,12}$ indicating the normal quality of alendronate-treated bone. Iliac-crest biopsies in patients treated with alendronate for up to three years show normal bone without evidence of mineralization defects. ${ }^{13}$

In 1990 two multicenter dose-ranging studies were initiated in several countries to determine the efficacy of continuous oral alendronate therapy in postmenopausal women with osteoporosis. These randomized, double-blind, placebo-controlled studies had identical designs. Bone mineral density of the spine was chosen as the primary end point on the basis of epidemiologic evidence demonstrating a strong and consistent relation between low bone mass and an increased risk of fracture..$^{14,15}$ The studies also evaluated the incidence of vertebral fractures, the progression of vertebral deformities, height loss, and the incidence of adverse effects. We report the combined results of these two trials.

\section{MeTHODS}

\section{Study Population}

One multicenter study was conducted in the United States, and the other in Australia, Canada, Europe, Israel, Mexico, New Zealand, and South America. Women who were 45 to 80 years old and postmenopausal ( $\geqslant 5$ years since menopause) with osteoporosis (defined as a bone mineral density of the lumbar spine that was at least $2.5 \mathrm{SD}$ below the mean value in premenopausal white women) were eligible for participation. These enrollment criteria were selected to represent the general population of women with osteoporosis (i.e., women with a low bone mass, with or without fractures). We excluded women with other causes of osteoporosis (e.g., treatment with glucocorticoids) or other disorders of bone and mineral metabolism (e.g., vitamin D deficiency, Paget's disease, or hyperparathyroidism); active peptic ulcer disease, abnormal renal function (serum creatinine level, $>1.5 \mathrm{mg}$ per deciliter [130 $\mu \mathrm{mol}$ per liter]), or abnormal hepatic function; abnormalities of the lumbar spine precluding the assessment of bone mineral density at a minimum of three lumbar vertebrae or a history of hip fracture; or any prior treatment with bisphosphonates or treatment within the preceding 12 months with estrogen, progestin, calcitonin, fluoride, or an anabolic steroid. Women were not excluded on the basis of race. All the women provided written informed consent, and the study protocols were approved by the institutional review board at each participating center.

\section{Treatment}

The women were randomly assigned to receive placebo ( 40 percent of the women) or 5,10 , or $20 \mathrm{mg}$ of alendronate per day (20 percent in each dose group) for two years, to be followed by open-label therapy during the third year. Before any of the women had reached the 24-month visit, the protocol was modified to include a third year of double-blind therapy, and the women receiving $20 \mathrm{mg}$ of alendronate per day were switched (blindly) to a dose of $5 \mathrm{mg}$ per day for the third year. This change was made because the results of another study had demonstrated that a dose of $20 \mathrm{mg}$ per day was more than necessary to obtain the maximal increase in bone mineral density. ${ }^{16}$ All the women received a daily supplement of calcium carbonate providing $500 \mathrm{mg}$ of elemental calcium.

\section{End Points}

The bone mineral density of the lumbar spine, femoral neck, trochanter, forearm, and total body was measured by dual-energy x-ray absorptiometry with the use of Hologic ODR-1000 or 1000/W (Hologic, Waltham, Mass.), Lunar DPX-L (Lunar, Madison, Wis.), or Norland XR-26 (Norland, Fort Atkinson, Wis.) densitometers. All scans were reviewed (without knowledge of the treatment assignment) at a central facility, which provided factors to correct for calibration drift in the machines as necessary.

Lateral spine films were obtained at base line and after one, two, and three years of therapy to detect vertebral fractures and the progression of vertebral deformities. Analysis of these end points was based on the change from base line (or the first available film) to the latest follow-up film. Films of the thoracic and lumbar spine were obtained with the standard values for target-to-film distance and centering used at each study center. The films were sent to the radiology center, where vertebral heights were determined by observers unaware of the treatment assignment or film sequence. All films from each woman were digitized at the same time. Three points were placed along the superior edge and three along the inferior edge of each vertebra from the fourth thoracic vertebra (T4) to the fifth lumbar vertebra (L5), demarcating the anterior, middle, and posterior heights of each vertebral body. A computer mouse with cross-hairs and a commercially available digitization board were used to enter the data as $\mathrm{X}$ and $\mathrm{Y}$ coordinates, and vertebral heights were calculated to the nearest $0.1 \mathrm{~mm}$ with the use of computer software. Corrections for magnification errors were made when appropriate.

The presence of vertebral fractures at base line (previous fractures) was determined by comparing each woman's base-line vertebralheight ratios with those of a reference group. ${ }^{17}$ The ratios were calculated as follows: the anterior and middle heights were compared with the posterior height of the same vertebra, and the posterior height was compared with the posterior height of an adjacent vertebra. Any vertebral-height ratio more than $3 \mathrm{SD}$ below the corresponding reference ratio was considered to be a previous vertebral fracture. ${ }^{17} \mathrm{~A}$ new fracture was defined as a reduction of at least 20 percent, with an absolute decrease of at least $4 \mathrm{~mm}$, in the height of any vertebral body between base line and follow-up.

Vertebral deformities were assessed with the Spine Deformity Index, which was developed as a continuous measure of vertebral deformities in patients with a history of vertebral fractures. The index sums deformations of multiple vertebrae into a single numerical value. ${ }^{18}$ Each vertebral height (T5 through L5) is divided by the corresponding T4 height (anterior, middle, or posterior) to generate a maximum of 39 vertebral-height ratios, which are corrected for differences in stature. Each ratio is then compared with population norms, and the absolute differences for ratios that fall below the minimal population norm are added, to arrive at the total Spine Deformity Index. We expected that a sizable proportion of the women with osteoporosis in our study would have no measurable deformities initially (i.e., a Spine Deformity Index of zero) and that no deformities would develop during the study. Hence, the primary use of the Spine Deformity Index was to compare the proportion of women in each group with increased indexes during the study.

Height was measured at base line and at 3, 6, 9, 12, 18, 24, 27, 30, and 36 months with a Harpenden stadiometer (Holtain, Crymmych, Pembrookshire, United Kingdom), which measures height to the nearest millimeter. Three measurements were obtained for each woman at each time point, and two additional measurements were made if any two values differed by more than $4 \mathrm{~mm}$. The value for height was the average of all three or five measurements obtained at each visit.

All reported symptomatic nonvertebral fractures were recorded, with no attempt to exclude fractures on the basis of the degree of trauma.

\section{Statistical Analysis}

From the outset, the plan was to pool the data from the two, identically designed studies and from the three alendronate groups in each study, since we anticipated that neither trial alone, nor any one dose group, would be sufficiently large to allow the detection of a significant effect of alendronate on the incidence of new fractures.

Changes in bone mineral density at each site (expressed as the percentage of increase or decrease from the base-line value) were calcu- 
lated at 3, 6, 12, 18, 24, 30, and 36 months. All analyses reflect the correction factors calculated at the central facility, which were determined from standard phantom spine measurements made during the study.

For the analysis of the proportion of women with one or more new vertebral fractures, the Breslow-Day test was used to determine whether there was any interaction between treatment group and study (since there were two studies). Because no interaction was evident $(\mathrm{P}=0.43)$, the study designs were identical, and the data pooling was specified in advance, the pooling of data from the two studies was valid. After the data had been pooled, the Cochran-Mantel-Haenszel test was used to compare the placebo group with the alendronate group. Estimates of the relative risk associated with alendronate as compared with placebo and 95 percent confidence intervals were computed.

A chi-square test was used to compare the proportions of women with progressive vertebral deformities (i.e., women with an increased Spine Deformity Index) in the placebo and alendronate groups. For the analysis of changes in height from base line, we used an analysisof-variance model that included terms for the treatment group, center, and interaction between the treatment and the center. This last term was removed from the analysis, since there was no statistical evidence of such an interaction. Slopes (for changes in height over time) were calculated for women who had at least three height measurements and were evaluated in a fashion similar to that described above, except that a weighted analysis of variance was used, with the weights inversely proportional to the variance of the estimated slope for each woman. ${ }^{19}$ Nonvertebral fractures were analyzed with the Cox proportional-hazards model, with each of the two studies as a stratification factor.

All analyses of the efficacy of alendronate were based on the intention-to-treat principle; that is, all women who had at least one measurement after randomization were included in the evaluation, irrespective of whether they were still taking the study drug. Treatment effects for certain prespecified patient characteristics (e.g., age and the presence or absence of a vertebral fracture at base line) were summarized for all end points, but no $\mathrm{P}$ values were computed.

\section{Results}

The base-line characteristics of the women in the treatment and placebo groups were similar (Table 1), and there were no differences between the two studies in the risk factors for fracture (data not shown). A total of 87.4 percent of the women were white, 0.4 percent were black, and 12.2 percent were of other races. Of the 994 women randomly assigned to treatment, 909 (91 percent) completed at least one year of the study. Paired spine films were analyzed for 881 (97 percent) of these women. Of the other 28 women, 21 had films that could not be digitized because of their poor quality, 4 had follow-up films that could not be found, and 3 declined follow-up radiography. The 113 women not included in the analysis of vertebral fractures did not differ from the other 881 women (data not shown). About 20 percent of the women in each group had vertebral fractures at base line (Table 1).

The Spine Deformity Index, which requires paired films with at least 13 vertebrae that can be fully evaluated, was calculated for 835 (95 percent) of the women included in the vertebral-fracture analysis. A total of 921 women had height values recorded at base line and at least one follow-up visit for the analysis of absolute loss of height; 902 women with values for at least three time points were included in the analysis of the rate of change in height. All women were included in the analysis of nonvertebral fractures.

\section{Bone Mineral Density}

There were significant increases in the bone mineral density of the spine, femoral neck, trochanter, and total
Table 1. Base-Line Characteristics of the 881 Women Included in the Analysis of Vertebral Fractures.*

\begin{tabular}{|c|c|c|}
\hline CHARACteristic & $\begin{array}{l}\text { Placebo Group } \\
\quad(\mathrm{N}=355)\end{array}$ & $\begin{array}{l}\text { ALENDRONATE GROUP } \\
\qquad(\mathrm{N}=526)\end{array}$ \\
\hline Mean age (yr) & 64 & 64 \\
\hline Mean yr since menopause & 17 & 16 \\
\hline Mean body-mass index & 24.1 & 24.2 \\
\hline Vertebral fractures ( $\%$ of women) & 21.2 & 20.2 \\
\hline No vertebral deformities ( $\%$ of women) $\dagger$ & 52.6 & 57.0 \\
\hline Mean Spine Deformity Index & 0.49 & 0.48 \\
\hline \multicolumn{3}{|l|}{ Mean bone mineral density $\left(\mathrm{g} / \mathrm{cm}^{2}\right)$} \\
\hline \multicolumn{3}{|l|}{ Lumbar spine } \\
\hline Hologic & 0.71 & 0.71 \\
\hline Lunar & 0.82 & 0.81 \\
\hline Norland & 0.68 & 0.67 \\
\hline \multicolumn{3}{|l|}{ Femoral neck } \\
\hline Hologic & 0.60 & 0.60 \\
\hline Lunar & 0.74 & 0.72 \\
\hline Norland & 0.67 & 0.66 \\
\hline \multicolumn{3}{|l|}{ Trochanter } \\
\hline Hologic & 0.53 & 0.52 \\
\hline Lunar & 0.62 & 0.61 \\
\hline Norland & 0.56 & 0.53 \\
\hline \multicolumn{3}{|l|}{ Total body } \\
\hline Hologic & 0.93 & 0.92 \\
\hline Lunar & 0.95 & 0.94 \\
\hline Norland & 1.03 & 1.04 \\
\hline Mean interval between films (yr) & 2.8 & 2.8 \\
\hline
\end{tabular}

*The body-mass index was calculated as the weight in kilograms divided by the square of the height in meters. Measurements of bone mineral density are shown according to the site of the measurement and the type of densitometer.

$\dagger$ Data are for women with a Spine Deformity Index of zero.

†Data are for women with a Spine Deformity Index higher than zero.

body at 36 months in all three alendronate groups, and significant losses at all sites in the placebo group (Fig. 1). The 10-mg dose was significantly more effective than the 5-mg dose at all skeletal sites and was as effective as $20 \mathrm{mg}$ followed by $5 \mathrm{mg}$. The mean $( \pm \mathrm{SE})$ differences in bone mineral density between the women receiving $10 \mathrm{mg}$ of alendronate daily and those receiving placebo were $8.8 \pm 0.4$ percent in the spine, $5.9 \pm 0.5$ percent in the femoral neck, $7.8 \pm 0.6$ percent in the trochanter, and $2.5 \pm 0.3$ percent in the total body $(\mathrm{P}<0.001$ for all comparisons). At two years, $10 \mathrm{mg}$ was as effective as $20 \mathrm{mg}$ (Fig. 1). As expected with an antiresorptive agent, the bone mineral density at each site increased most rapidly during the first six months of treatment.

The 10-mg dose of alendronate resulted in increases in bone mineral density at all sites during all three years, although the increase in total-body bone mineral density during year 3 was not significant (Fig. 1). In contrast, the bone mineral density in the spine, hip, and total body did not increase significantly during the third year in the patients treated with $5 \mathrm{mg}$ of alendronate per day or $20 \mathrm{mg}$ followed by $5 \mathrm{mg}$. Thus, the progressive increases in bone mineral density at each site during the 36 -month study period were most marked in response to $10 \mathrm{mg}$ of alendronate per day, with no plateau in the effect during the entire 3-year study period at either the spine or the hip. In the midforearm, an almost entirely cortical site, the 10-mg dose also resulted in $2.2 \pm 0.4$ percent greater bone mineral density than placebo $(\mathrm{P}<0.001)$.

The increases in bone mineral density in the spine were similar regardless of the bone mineral density, rate of bone turnover, age, or creatinine clearance at 
base line. Over 96 percent of the women treated with $10 \mathrm{mg}$ of alendronate for three years had measurable increases in bone mineral density in the spine (data not shown).

\section{Vertebral Fractures}

During the study, 22 of the 355 women in the placebo group (6.2 percent) had at least one new vertebral fracture, as compared with 17 of the 526 women in the combined alendronate groups (3.2 percent, $\mathrm{P}=0.03)$ (Table 2). Only two women had new vertebral fractures only in vertebrae with previous fractures. The relative risk of a new fracture among the women treated with alendronate, as compared with those receiving placebo, was 0.52 (95 percent confidence interval, 0.28 to 0.95 ). This decreased risk among the women receiving alendronate was found in both studies and in women stratified according to age (less than 65 years or 65 years or older) or the presence or absence of a previous vertebral fracture (Table 2). The risk of a vertebral fracture was also decreased in all dose groups, with new vertebral fractures in 2.9 percent of the women receiving $5 \mathrm{mg}$ of alendronate, 2.8 percent of those receiving $10 \mathrm{mg}$, and 4.1 percent of those receiving $20 \mathrm{mg}$ followed by $5 \mathrm{mg}$, as compared with 6.2 percent of the women in the placebo group.

Among the women who had new vertebral fractures, the proportion with two or more fractures was much lower in the combined alendronate groups (18 percent) than in the placebo group (68 percent). On an absolute basis, 4.2 percent of the women receiving placebo (15 of 355) had two or more vertebral fractures, as compared with 0.6 percent of those treated with alendronate (3 of 526). Because of the combination of fewer affected women and fewer fractures per woman, the number of vertebral fractures per 100 women was substantially lower in the combined alendronate groups than in the placebo group (4.2 vs. 11.3). Among the women with vertebral fractures, the ratio of wedge or crush fractures to end-plate fractures was higher in the placebo group than in the combined alendronate groups (data not shown).

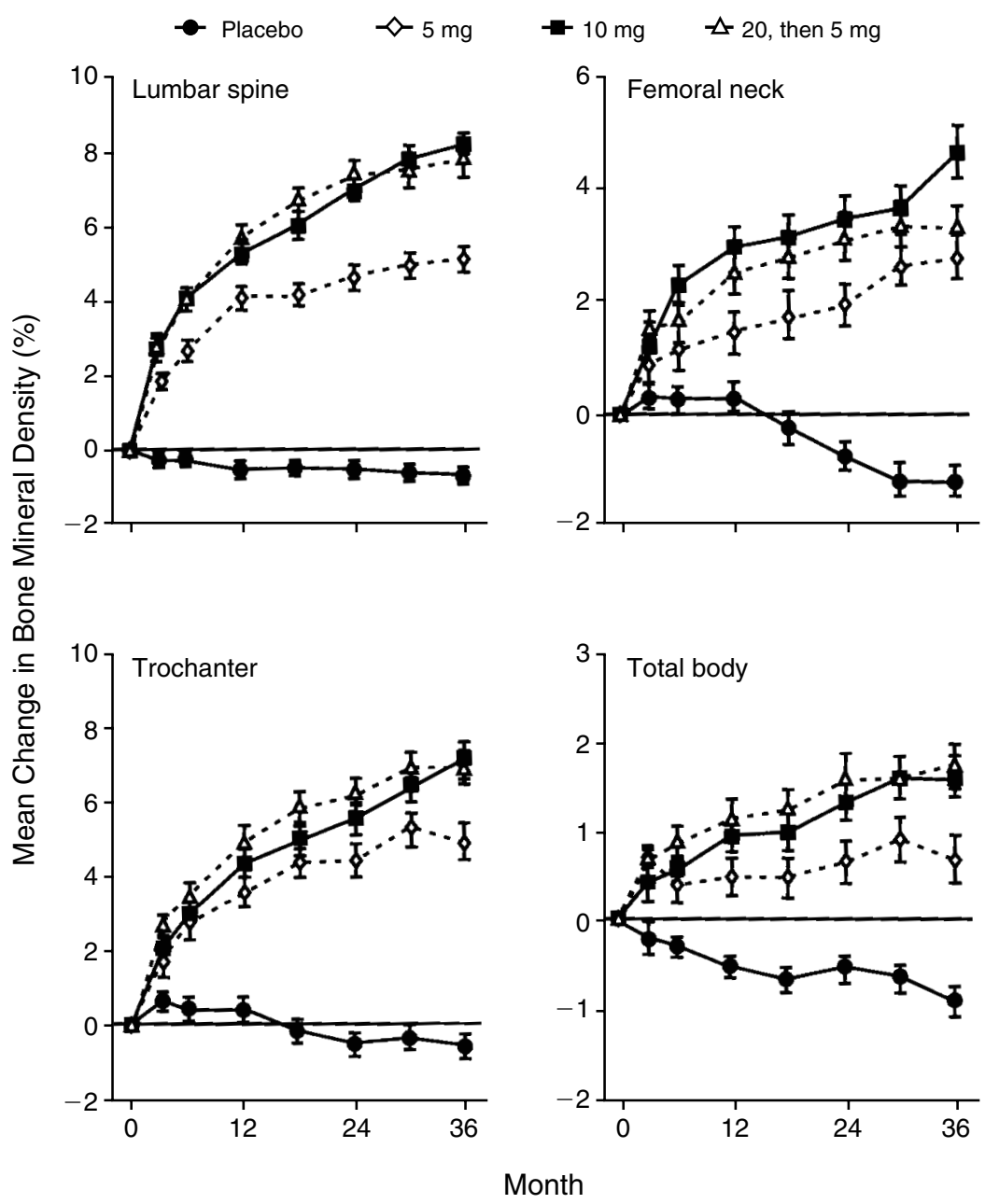

Figure 1. Mean $( \pm \mathrm{SE})$ Changes in Bone Mineral Density from Base-Line Values in Women with Postmenopausal Osteoporosis Receiving Alendronate or Placebo for Three Years.

Data are shown for bone mineral density (measured by dual-energy $\mathrm{x}$-ray absorptiometry) of the spine, femoral neck, trochanter, and total body. Data for the alendronate group are shown according to the dose: 5 or $10 \mathrm{mg}$ per day for three years or $20 \mathrm{mg}$ per day for two years followed by $5 \mathrm{mg}$ per day in year 3 .

\section{Spine Deformity Index}

The Spine Deformity Index increased in 33 percent of the women receiving alendronate but in 41 percent of those receiving placebo $(\mathrm{P}=0.028)$. This beneficial effect of alendronate was consistent in both studies, in women younger than 65 or 65 or older, and in women with or without vertebral deformities at base line (data not shown). There was a difference of borderline significance $(\mathrm{P}=0.054$ by the Wilcoxon ranksum test) in the distribution of the change from the base-line Spine Deformity Index in the placebo and alendronate groups. The mean change in the Spine Deformity Index was $0.08 \pm 0.02$ in the placebo group and $0.04 \pm 0.01$ in the alendronate group.

\section{Height}

The mean loss of height after three years of treatment was 35 percent less in the alendronate group than in the placebo group $(3.0 \mathrm{~mm}$ vs. $4.6 \mathrm{~mm}, \mathrm{P}=0.005)$. The effect of alendronate in preventing loss of height was greater in the older women ( $\geqslant 65$ years) and in the subgroup with previous fractures than in the younger women or the subgroup without previous fractures (data not shown). The annualized rate of height loss was about 40 percent lower in the women treated with alendronate than in those receiving 
Table 2. Women with New Vertebral Fractures during the ThreeYear Study Period.*

\begin{tabular}{lcc}
\hline \hline Group of Women & Placebo Group & Alendronate Group \\
& $\%$ of women with fractures (no./total no.) \\
All & $6.2(22 / 355)$ & $3.2(17 / 526) \dagger$ \\
Age, $<65 \mathrm{yr}$ & $4.7(9 / 190)$ & $3.7(11 / 294)$ \\
Age, $\geqslant 65 \mathrm{yr}$ & $7.9(13 / 165)$ & $2.6(6 / 232)$ \\
With previous fractures & $19.1(13 / 68)$ & $13.4(13 / 97)$ \\
Without previous fractures & $2.0(5 / 253)$ & $1.0(4 / 384)$ \\
In U.S. study & $4.5(8 / 177)$ & $1.6(4 / 258)$ \\
In multinational study & $7.9(14 / 178)$ & $4.9(13 / 268)$ \\
\hline
\end{tabular}

*The numbers of women with and without previous fractures do not sum to 881 , because only women with pretreatment films that could be fully evaluated were included in the baseline analysis of fractures.

$\dagger \mathrm{P}=0.03$, relative risk $=0.52$ (95 percent confidence interval, 0.28 to 0.95 ).

placebo, resulting in a difference between the groups of $0.7 \mathrm{~mm}$ per year $(\mathrm{P}<0.001)$.

Loss of height in the women without new vertebral fractures was small and similar in the treatment and placebo groups (2.8 and $3.3 \mathrm{~mm}$, respectively) (Fig. 2). Among the women with new vertebral fractures, however, those in the placebo group lost a mean of $23.3 \mathrm{~mm}$ in height, whereas the mean loss of height in the alendronate group $(5.9 \mathrm{~mm})$ was only slightly greater than the mean loss in the women without new fractures.

\section{Nonvertebral Fractures}

Nonvertebral fractures occurred in 83 women, with a trend toward a reduced number of fractures in the alendronate group. Of the 397 women in the placebo group, 38 had a total of 47 nonvertebral fractures during 1015 patient-years of follow-up, whereas 45 of the 597 alendronate-treated women had a total of 46 nonvertebral fractures during 1525 patient-years of followup. In the placebo group, the cumulative incidence of women with nonvertebral fractures after three years was 10.7 percent, with an overall rate of 3.7 women with fractures per 100 patient-years at risk. In the alendronate group, the cumulative incidence was 8.5 percent, with an overall rate of 3.0 women with fractures per 100 patient-years at risk. The estimated risk of nonvertebral fractures in the women treated with alendronate was 0.79 (95 percent confidence interval, 0.52 to 1.22 ). The difference in the cumulative proportions of women without nonvertebral fractures in the alendronate and placebo groups appeared to increase in the third year (Fig. 3). Table 3 shows the data for all nonvertebral fractures. There were no reports of stress fractures, fracture malunion, or delayed healing of fractures.

\section{Adverse Effects}

Alendronate was generally well tolerated, with no greater clinical or laboratory evidence of adverse effects than with placebo. Overall, 16.3 percent of the women discontinued therapy, with similar frequencies in the placebo group and all three alendronate groups (Table 4). Discontinuation was due to clinical adverse effects in 6.0 percent of the women receiving placebo, 5.4 percent of those receiving $5 \mathrm{mg}$ of alendronate, 4.1 percent of those receiving $10 \mathrm{mg}$, and 8.0 percent of those receiving $20 \mathrm{mg}$ for two years followed by $5 \mathrm{mg}$ in the third year. Dose-dependent upper gastrointestinal irritation is the primary side effect associated with several other bisphosphonates, which are administered at higher doses. ${ }^{20,21}$ The women in the placebo group and all three alendronate groups had similar rates of adverse upper gastrointestinal effects, resulting in the discontinuation of treatment in only 2.0 percent of the women receiving placebo, 3.5 percent of those receiving $5 \mathrm{mg}$ of alendronate, 1.0 percent of those receiving 10 $\mathrm{mg}$, and 2.0 percent of those receiving $20 \mathrm{mg}$ followed by $5 \mathrm{mg}$. The most common adverse effects considered to be drug-related by the blinded investigators were abdominal pain (in 6.6 percent of the women receiving 10 $\mathrm{mg}$ of alendronate and 4.8 percent of those receiving placebo), musculoskeletal pain (in 4.1 and 2.5 percent, respectively), nausea (in 3.6 and 4.0 percent), dyspepsia (in 3.6 and 3.5 percent), constipation (in 3.1 and 1.8 percent), and diarrhea (in 3.1 and 1.8 percent).

\section{Discussion}

Daily treatment with oral alendronate for three years resulted in increases in the bone mineral density of the spine, hip, and total body in women with postmenopausal osteoporosis, and these effects were associated with reductions in the incidence of vertebral fractures, vertebral deformities, and loss of height, as well as a trend toward a reduction in the incidence of fractures at nonvertebral sites. The $10-\mathrm{mg}$ dose produced progressive increases in bone mineral density, which were larger than the increases associated with the 5-mg dose at all skeletal sites and at all time points after six months. The efficacy of $10 \mathrm{mg}$ of alendronate per day was similar to that of $20 \mathrm{mg}$ per day for two years and did not plateau during up to three years of therapy a finding consistent with the reversal of a negative bone balance at the level of individual remodeling units. Although $20 \mathrm{mg}$ per day for two years followed by $5 \mathrm{mg}$

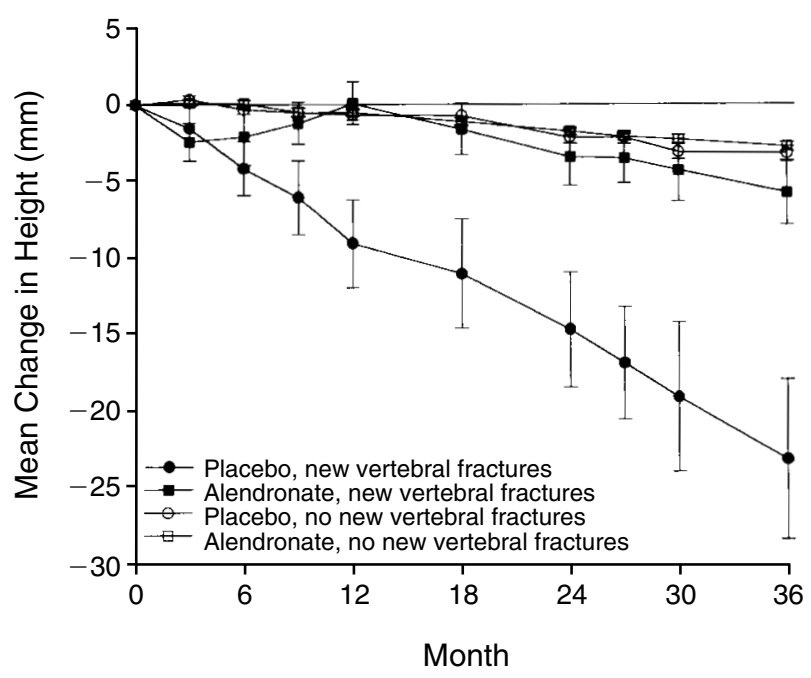

Figure 2. Mean $( \pm S E)$ Changes in Height from Base-Line Values among Women with or without New Vertebral Fractures in the Alendronate and Placebo Groups.

Changes in height were calculated as the mean of three to five measurements per woman, made with a Harpenden stadiometer. The data for the women in the three alendronate groups have been pooled. 
per day in the third year is a 50 percent greater cumulative dose than $10 \mathrm{mg}$ per day for three years, the greater increase in bone mineral density during the third year in the 10-mg group indicates that the current dose of alendronate, not the total or cumulative dose, results in the changes in bone mass. All three doses increased the bone mass at all sites, including the total body, which is consistent with a systemic effect rather than a redistribution of the bone mass from cortical to trabecular bone. Continuous therapy with $10 \mathrm{mg}$ of alendronate per day provided maximal efficacy, was well tolerated, and is therefore the optimal dose for the treatment of osteoporosis in postmenopausal women.

Most prospective, randomized trials with fractures as an end point have recruited women who had multiple vertebral fractures at base line and were therefore at very high risk for subsequent fractures. ${ }^{22-29}$ Although these women had higher rates of fracture than the women in our study,${ }^{14}$ the applicability of the results of these trials to the general population of women with osteoporosis may be limited. A recent positive study of the effects of vitamin $\mathrm{D}_{3}$ and calcium on hip fractures enrolled only elderly institutionalized women, nearly half of whom had biochemical evidence of vitamin D deficiency. ${ }^{30}$ In contrast, the women in the two studies reported here were selected because of decreased bone mineral density in the lumbar spine but were not required to have a history of vertebral or other fractures. Therefore, the results of these studies should be applicable to most women with postmenopausal osteoporosis.

The selection of the optimal dose of alendronate for the treatment of osteoporosis was based on bone mineral density, rather than fractures, as the primary end point, since dose-ranging studies that used fractures as the primary end point would require many more women. To verify the hypothesis that increases in bone mass induced by alendronate would reduce the incidence of

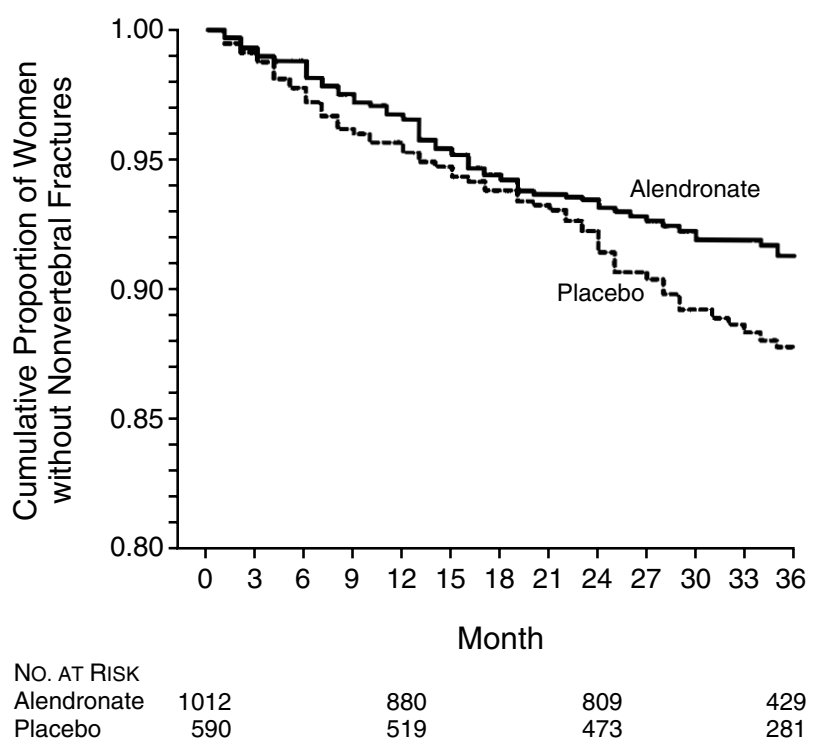

Figure 3. Cumulative Proportion of Women without Nonvertebral Fractures.

The data were calculated by the life-table method. The data for the women in the three alendronate groups have been pooled.
Table 3. Women with New Nonvertebral Fractures and Sites of Fracture during the Three-Year Study Period.

\begin{tabular}{lcc}
\hline \hline Nonvertebral Fractures & $\begin{array}{c}\text { Placebo Group } \\
(\mathrm{N}=397)\end{array}$ & $\begin{array}{c}\text { Alendronate Group } \\
(\mathrm{N}=597)\end{array}$ \\
No. of women (\%) & $38(9.6)$ & $45(7.5)$ \\
No. of fractures & 47 & 46 \\
Site of fracture - no. of women (\%) & & \\
Hip & $3(0.8)$ & $1(0.2)$ \\
Pelvis & $4(1.0)$ & 0 \\
Wrist or forearm & $16(4.0)$ & $8(1.3)$ \\
Upper arm & $4(1.0)$ & $2(0.3)$ \\
Leg or patella & $6(1.5)$ & $4(0.7)$ \\
Rib & $6(1.5)$ & $6(1.0)$ \\
Ankle, foot, or toe & $6(1.5)$ & $15(2.5)$ \\
Hand or finger & $1(0.3)$ & $1(0.2)$ \\
Clavicle or sternum & $1(0.3)$ & $4(0.7)$ \\
Shoulder & 0 & $2(0.3)$ \\
Face or skull & 0 & $3(0.5)$ \\
\hline
\end{tabular}

fractures, we compared all three alendronate groups with the placebo group. Because the regimen of $10 \mathrm{mg}$ of alendronate per day for three years produced a greater increase in bone mineral density than the other doses (the women in the $10-\mathrm{mg}$ group had 8.8 percent greater density at the spine than those in the placebo group), as well as a larger decrease in the incidence of vertebral fractures (55 percent), the pooling of the dose groups may underestimate the efficacy of the $10-\mathrm{mg}$ dose in preventing fractures.

A number of previous trials have used fracture rates as the primary unit of analysis in determining the effi-

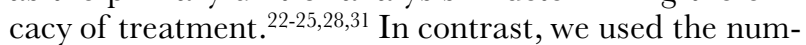
ber of women with new vertebral fractures, since multiple fractures in the same woman are not independent events. ${ }^{32}$ Nevertheless, fracture rates are of interest. Treatment with alendronate, as compared with placebo, decreased the average number of vertebral fractures per woman by 63 percent. The decrease in the number of fractures and the smaller proportions of crush and wedge fractures account for the much smaller loss of height among the women with new fractures in the alendronate group than among the women with new fractures in the placebo group.

We found a trend toward a decreased proportion of women with new nonvertebral fractures in the alendronate group, with a 21 percent reduction in absolute risk among the women treated with alendronate, as compared with those receiving placebo. The use of pooled data on nonvertebral fractures as an indication of the efficacy of treatment represents a post hoc analysis and should be viewed with some caution. Nevertheless, the reduction in new nonvertebral fractures in the alendronate group is consistent with the progressive increases in the bone mineral density of the hip and total body induced by treatment with alendronate, as well as with the reduction in vertebral fractures. These results suggest that alendronate increases bone strength at appendicular sites, as well as in the axial skeleton.

The results of these trials are consistent both internally and with prospective epidemiologic studies of the relation between bone mineral density of the lumbar spine and the risk of vertebral fracture..$^{14,15}$ The women in the placebo group with the lowest base-line bone mineral density of the lumbar spine had the highest in- 
Table 4. Women Who Discontinued Therapy.

\begin{tabular}{ccccc}
\hline \hline Year of Study & $\begin{array}{c}\text { Placebo Group } \\
(\mathrm{N}=397)\end{array}$ & \multicolumn{3}{c}{ Alendronate Group $(\mathrm{N}=597)$} \\
& & $\begin{array}{c}5 \mathrm{mg} \\
(\mathrm{N}=202)\end{array}$ & $\begin{array}{c}10 \mathrm{mg} \\
(\mathrm{N}=196)\end{array}$ & $\begin{array}{c}20 / 5 \mathrm{mg} \\
(\mathrm{N}=199)\end{array}$ \\
& & no. of women $(\%)$ & \\
& & & \\
1 & $23(5.8)$ & $17(8.4)$ & $16(8.2)$ & $17(8.5)$ \\
2 & $27(6.8)$ & $6(3.0)$ & $6(3.1)$ & $6(3.0)$ \\
3 & $15(3.8)$ & $12(5.9)$ & $4(2.0)$ & $13(6.5)$ \\
Total & $65(16.4)$ & $35(17.3)$ & $26(13.3)$ & $36(18.1)$ \\
\hline
\end{tabular}

cidence of new vertebral fractures, the highest rate of progression of vertebral deformities, and the greatest loss in height during the study, whereas the women with the highest base-line bone mineral density of the spine had the lowest values for these three end points (data not shown). In addition, the overall increase in spine bone mineral density in the alendronate group (approximately 8 percent, as compared with a decrease in the placebo group) was associated with an almost 50 percent decrease in the proportion of women with new vertebral fractures. These findings confirm the results of other studies indicating that the relative risk of a vertebral fracture approximately doubles for each reduction in spine bone mineral density equivalent to $1 \mathrm{SD}$ (approximately 10 percent). ${ }^{14,15}$

In summary, daily treatment with oral alendronate progressively increases the bone mass of the spine, hip, and total body and reduces the risk of vertebral fractures, the progression of vertebral deformities, and height loss in postmenopausal women with osteoporosis.

We are indebted to Ms. Ann Barash for assistance in the preparation of the manuscript and to the study nurses and technicians for assistance in conducting the studies.

\section{APPENDIX}

In addition to the authors, the following investigators were members of the Alendronate Phase III Osteoporosis Treatment Study Group: M.Z. Baker, Oklahoma City; M. Bliziotes, Portland, Oreg.; H.G. Bone III, Detroit; R. Correa-Rotter and J.C. Peña, Mexico City; D.C. Cumming, Edmonton, Alta., Canada; J.P. Devogelaer and C. Nagant de Deuxchaisnes, Brussels, Belgium; R.D. Emkey, Reading, Pa.; P. Geusens, Diepenbeek, Belgium; D. Hosking, Nottingham, United Kingdom; P. Jaeger, Bern, Switzerland; G.C. Johnston, Jr., Indianapolis; J.M. Kaufman and A. Vermeulen, Ghent, Belgium; M.O. Leite, São Paulo, Brazil; J. León, Bogotá, Colombia; R. Samuel, Tel Aviv, Israel; R. Marcus and M.L. Villa, Palo Alto, Calif.; H. McIlwain, J.C. Silverfield, and J.L. Miller, Tampa, Fla.; C.J. Menkes, Paris; P.J. Meunier, Lyon, France; I.R. Reid, Auckland, New Zealand; A. Romanowicz, Buenos Aires, Argentina; R.D. Tonino, Burlington, Vt.; J. Tucci, Providence, R.I.; R.D. Wasnich, Honolulu; N.B. Watts, Atlanta; and R.S. Weinstein and A.L. Mulloy, Augusta, Ga. Radiology Center, Bad Pyrmont, Germany: T. Bruckner and W. Pollähne. Bone Densitometry Center, Portland, Oreg.: E.S. Orwoll, S. Oviatt-Orwoll, and K. Linton. Merck Research Laboratories, Rahway, N.J.: G. Arena, K. Plezia, C. Peverly, C.D. Maibach, D.R. Shapiro, D.E. Thompson, and R. Tierney.

\section{REFERENCES}

1. Riggs BL, Melton LJ III. The prevention and treatment of osteoporosis. N Engl J Med 1992;327:620-7.

2. Consensus development conference: diagnosis, prophylaxis, and treatment of osteoporosis. Am J Med 1993;94:646-50.

3. Burger H, van Daele PLA, Algra D, et al. Vertebral deformities as predictors of non-vertebral fractures. BMJ 1994;309:991-2.
4. Leichter I, Margulies JY, Weinreb A, et al. The relationship between bone density, mineral content, and mechanical strength in the femoral neck. Clin Orthop 1982;163:272-81.

5. Fleisch H. Bisphosphonates: pharmacology and use in the treatment of tumor-induced hypercalcaemic and metastatic bone disease. Drugs 1991;42: 919-44.

6. Schenk R, Eggli P, Fleisch H, Rosini S. Quantitative morphometric evaluation of the inhibitory activity of new aminobisphosphonates on bone resorption in the rat. Calcif Tissue Int 1986;38:342-9.

7. Shinoda H, Adamek G, Felix R, Fleisch H, Schenk R, Hagan P. Structureactivity relationships of various bisphosphonates. Calcif Tissue Int 1983;35: 87-99.

8. Marcus R. Cyclic etidronate: has the rose lost its bloom? Am J Med 1993; 95:555-6.

9. Axelrod DW, Teitelbaum SL. Results of long-term cyclical etidronate therapy: bone histomorphometry and clinical correlates. J Bone Miner Res 1994;9:Suppl 1:S136. abstract.

10. Garnero P, Shih WJ, Gineyts E, Karpf DB, Delmas PD. Comparison of new biochemical markers of bone turnover in late postmenopausal osteoporotic women in response to alendronate treatment. J Clin Endocrinol Metab 1994;79:1693-700.

11. Guy JA, Shea M, Peter CP, Morrissey R, Hayes WC. Continuous alendronate treatment throughout growth, maturation, and aging in the rat results in increases in bone mass and mechanical properties. Calcif Tissue Int 1993;53:283-8.

12. Balena R, Toolan BC, Shea M, et al. The effects of 2-year treatment with the aminobisphosphonate alendronate on bone metabolism, bone histomorphometry, and bone strength in ovariectomized nonhuman primates. J Clin Invest 1993;92:2577-86

13. Arlot MC, Meunier PJ, Chavassieux P, et al. Effects of long-term alendronate treatment for postmenopausal osteoporosis on bone histomorphometry. J Bone Miner Res 1995;10:Suppl 1:S199. abstract

14. Ross PD, Davis JW, Epstein RS, Wasnich RD. Pre-existing fractures and bone mass predict vertebral fracture incidence in women. Ann Intern Med 1991;114:919-23.

15. Melton LJ III, Atkinson EJ, O'Fallon WM, Wahner HW, Riggs BL. Longterm fracture prediction by bone mineral assessed at different skeletal sites. J Bone Miner Res 1993;8:1227-33.

16. Chesnut CH III, McClung MR, Ensrud KE, et al. Alendronate treatment of the postmenopausal osteoporotic woman: effect of multiple dosages on bone mass and bone remodeling. Am J Med 1995;99:144-52

17. Melton LJ III, Lane AW, Cooper C, Eastell R, O'Fallon WM, Riggs BL. Prevalence and incidence of vertebral deformities. Osteoporos Int 1993;3: 113-9.

18. Minne HW, Leidig G, Wuster C, et al. A newly developed spine deformity index (SDI) to quantitate vertebral crush fractures in patients with osteoporosis. Bone Miner 1988;3:335-49.

19. Gornbein JA, Lazaro CG, Little RJA. Incomplete data in repeated measures analysis. Stat Methods Med Res 1992;1:275-95.

20. Lufkin EG, Argueta R, Whitaker MD, et al. Pamidronate: an unrecognized problem in gastrointestinal tolerability. Osteoporos Int 1994;4:320-2.

21. Schiller JH, Rasmussen P, Benson AB III, et al. Maintenance etidronate in the prevention of malignancy-associated hypercalcemia. Arch Intern Med 1987; 147:963-6.

22. Lufkin EG, Wahner HW, O'Fallon WM, et al. Treatment of postmenopausal osteoporosis with transdermal estrogen. Ann Intern Med 1992;117:1-9.

23. Riggs BL, Hodgson SF, O'Fallon WM, et al. Effect of fluoride treatment on the fracture rate in postmenopausal women with osteoporosis. N Engl J Med 1990;322:802-9.

24. Kleerekoper M, Peterson EL, Nelson DA, et al. A randomized trial of sodium fluoride as a treatment for postmenopausal osteoporosis. Osteoporos Int 1991;1:155-61.

25. Pak CYC, Sakhaee K, Piziak V, et al. Slow-release sodium fluoride in the management of postmenopausal osteoporosis: a randomized controlled trial. Ann Intern Med 1994;120:625-32.

26. Mamelle N, Meunier PJ, Dusan R, et al. Risk-benefit ratio of sodium fluoride treatment in primary vertebral osteoporosis. Lancet 1988;2:361-5.

27. Watts NB, Harris ST, Genant HK, et al. Intermittent cyclical etidronate treatment of postmenopausal osteoporosis. N Engl J Med 1990;323:739.

28. Storm T, Thamsborg G, Steiniche T, Genant HK, Sørensen OH. Effect of intermittent cyclical etidronate therapy on bone mass and fracture rate in women with postmenopausal osteoporosis. N Engl J Med 1990;322:126571 .

29. Tilyard MW, Spears GFS, Thomson J, Dovey S. Treatment of postmenopausal osteoporosis with calcitriol or calcium. N Engl J Med 1992;326:35762.

30. Chapuy MC, Arlot ME, Duboeuf F, et al. Vitamin $\mathrm{D}_{3}$ and calcium to prevent hip fractures in elderly women. N Engl J Med 1992;327:1637-42.

31. Overgaard K, Hansen MA, Jensen SB, Christiansen C. Effect of salcatonin given intranasally on bone mass and fracture rates in established osteoporosis: a dose-response study. BMJ 1992;305:556-61.

32. Windeler J, Lange S. Events per person year - a dubious concept. BMJ 1995;310:454-6. 